\title{
ALBORES DEL PSICOTROPISMO EN SAN PEDRO DE ATACAMA. PIPAS VS. TABLETAS
}

\author{
THE DAWN OF PSICOTROPISM IN SAN PEDRO DE ATACAMA. \\ PIPES VS. TABLETS
}

Agustín Llagostera ${ }^{1}$

\begin{abstract}
Las condiciones de desarrollo cultural y de preservación de los restos arqueológicos se han conjugado para que en San Pedro de Atacama se disponga, tal vez, del único registro arqueológico del uso de dos prácticas diferentes de inhalación de sustancias psicoestimulantes: en forma de fumitorios utilizando pipas y en forma de polvos a través de tabletas y tubos.

En el presente artículo se expone la investigación realizada sobre estas dos tradiciones, a fin de determinar el momento en que sus manifestaciones comenzaron a hacerse presentes en esta localidad, las características de cada una de ellas y la parafernalia asociada que tuvieron en sus albores. Se contrasta la relación entre ambas tradiciones; se hace un seguimiento de ellas a través del tiempo; se describe las características morfológicas de las pipas y la iconografía de las tabletas tempranas; se indaga sobre su posible origen o procedencia; se realiza una comparación sincrónica de estos artefactos entre los diferentes sitios que registran su presencia; se analizan las variaciones diacrónicas en la secuencia de fases del desarrollo cultural de San Pedro de Atacama y se busca definir una caracterización sociocultural de sus portadores.
\end{abstract}

Palabras claves: arqueología, San Pedro de Atacama, prácticas psicotrópicas, pipas, tabletas para alucinógenos.

Cultural development and preservation have come together to make San Pedro de Atacama perhaps the only archaeological record of two different practices in the use of psychostimulating substances: inhalation in pipes and inhalation using tablets and tubes. This article describes research on these two traditions, in order to determine the time in which the practice was initiated in this place, along with the specific characteristics and the paraphernalia associated with them from the beginning. Relations are established between both traditions, which are traced through timet. The morphological characteristics of pipes and the iconography of the early tablets are described, looking into their possible origin or provenance. A synchronous comparison of these artifacts is carried out among different sites where their presence has been established. The diachronic variations in the sequence of the phases of cultural development of San Pedro de Atacama are also examined in order to define a socio-cultural characterization of their carriers.

Key words: Archaeology, San Pedro de Atacama, psychotropic practices, pipes, snuff tray.

En trabajos anteriores (Llagostera 1995, 2001, 2006) se han expuesto diferentes aspectos relacionados con el complejo alucinógeno de San Pedro de Atacama (SPA) (Figura 1), centrándose en aspectos como iconografía, estilos y secuencias, sus relaciones con el shamanismo, análisis en sitios determinados, así como su contextualización en la secuencia local, quedando en claro que en SPA el psicotropismo tuvo su expresión en todo el período agroalfarero, manifestándose caracterizaciones específicas de la parafernalia a través de las diversas fases del desarrollo cultural de esta localidad. En esta oportunidad centraremos el análisis en los momentos en que comienzan a emerger las evidencias de estas prácticas.
En los albores de las prácticas psicotrópicas en SPA se hacen presentes dos tradiciones de consumo de alucinógenos, las que, habiéndose originado en otros lugares del continente, comenzaron a ser incorporadas en esta localidad; este es un lapso interesante de conocer en cuanto a la manera en que esto se produjo y el significado que pudo tener para la sociedad atacameña.

Las condiciones de desarrollo cultural y la preservación del material arqueológico en el árido subsuelo desértico se han conjugado para que en SPA se disponga, tal vez, del único registro arqueológico del uso de dos prácticas psicotrópicas diferentes: la inhalación de alucinógenos en pipas y la inhalación de alucinógenos pulverizados utilizando tabletas y

$1 \quad$ Instituto de Investigaciones Antropológicas, Universidad de Antofagasta, Antofagasta, Chile. allagostera@vtr.net

Recibido: julio 2014. Aceptado: junio 2015. 

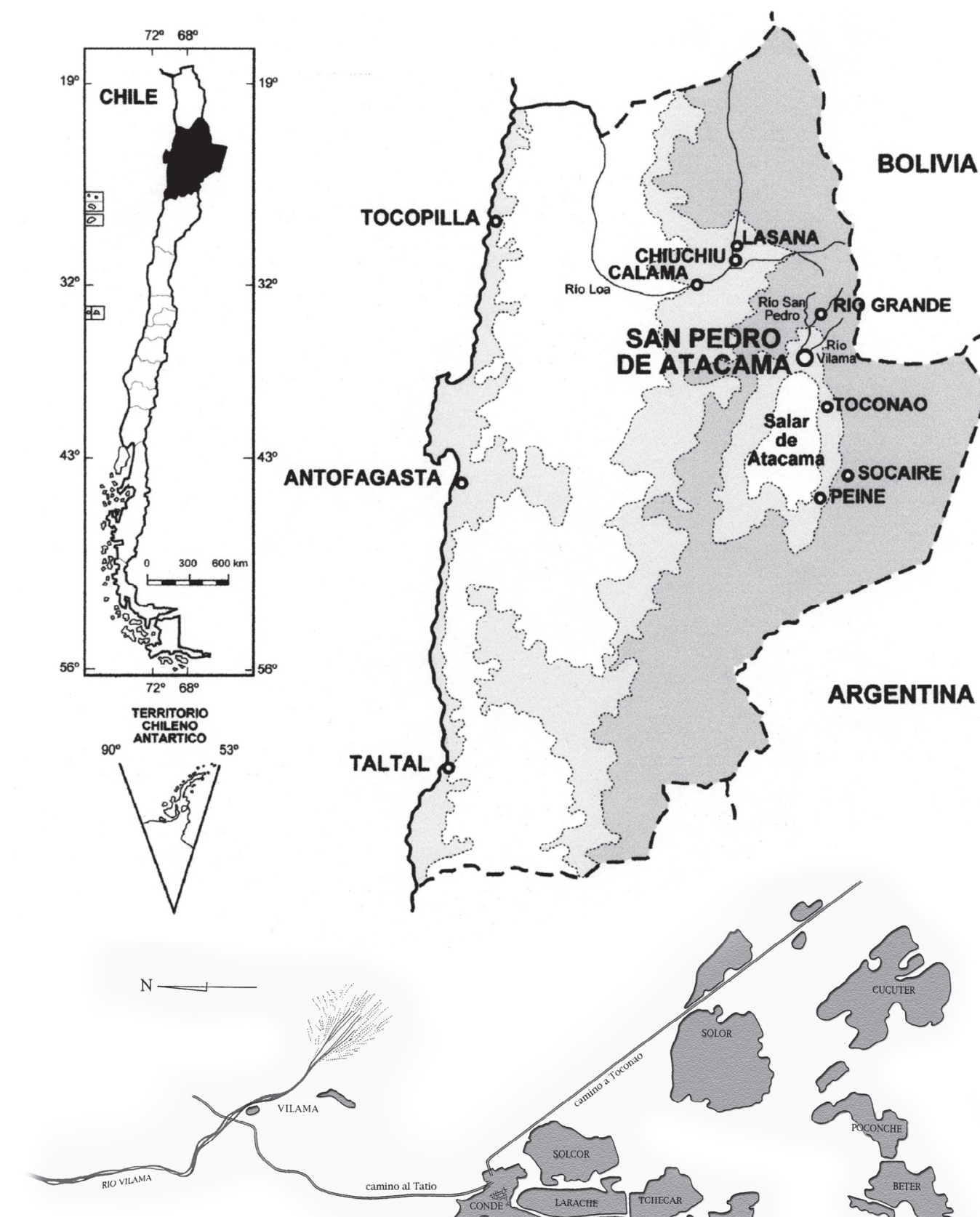

SAN PEDRO
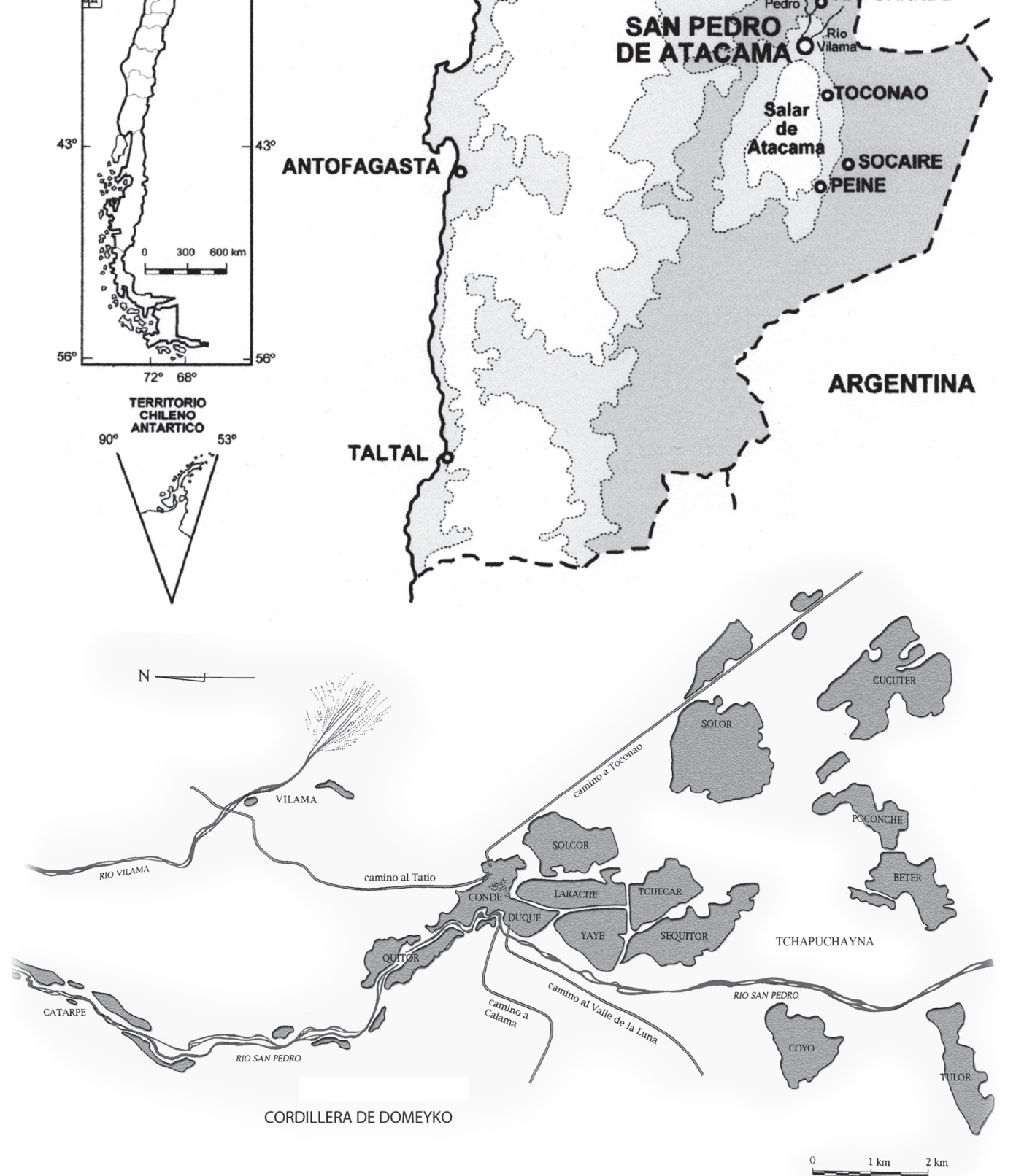

Figura 1. Mapa de referencia: (a) ubicación de San Pedro de Atacama y Toconao; (b) oasis de San Pedro de Atacama (ayllus). Map of reference: (a) location of San Pedro de Atacama and Toconao; (b) oasis of San Pedro de Atacama (ayllus). 
tubos. Esto nos pone en una situación de privilegio para el estudio de la transición de una tradición a otra y da la posibilidad de efectuar indagaciones acerca del proceso de su inserción en la sociedad atacameña prehispánica.

\section{Antecedentes}

El uso de pipas fue una práctica bastante difundida entre los pueblos precolombinos de los Andes Centro Sur, con referentes cronológicos tan tempranos como el segundo milenio anterior a nuestra era. Fernández Distel (1980) hace referencia a pipas encontradas en cuevas precerámicas del noroeste argentino, del tipo que Boman (1932) definió como "tubular", y las consigna hacia el 2.000 a.C. Por su parte, Ibarra y Querejazu (1986), al referirse a la cerámica Chiripa de Bolivia, comentan que se registran unos tubos largos con adornos incisos y en relieve, los que generalmente han sido considerados como "sopladores para el fuego", pero que ellos los interpretan como pipas, similares a las de la cultura de los Túmulos de Cochabamba. Para Chiripa se dan fechas de 1.290 a.C. a 22 d.C. y para Wankarani, donde también existe este tipo de artefactos, de 1.290 a 250 a.C. Pereira y colaboradores (1992), en trabajos en sitios formativos de Cochabamba, encuentran tubos similares, consignando fechas de 831 a 187 a.C.

El principal tipo de pipas presente en SPA es el referido "con hornillo vertical" (Boman 1932) (Figuras 2, 3, 4 y 5), para el cual la literatura arqueológica nos remite básicamente al noroeste argentino. En el mapa de dispersión geográfica de las pipas en Sudamérica publicado en el trabajo de Boman, este tipo de pipas aparece señalado para esa región y, aparentemente, incursionando hacia el suroeste de Brasil. Por su parte, Serrano (1966) las asigna al litoral, región central y noroeste de Argentina, acotando que las del noroeste se caracterizan por un hornillo infundibuliforme, una boquilla larga que constituye casi siempre una verdadera cámara de humo y una rama ascendente que puede ser lisa o con atributos zoomorfos o antropomorfos. El mismo autor concluye diciendo que el uso de las pipas es muy antiguo en el territorio argentino y que se las encuentra en culturas como Ciénaga, Candelaria y San Francisco.

Dougherty (1972) dice que es importante destacar que, mientras en el ámbito del sur y del este de Jujuy las pipas de fumar están presentes de manera casi constante, en el resto de la provincia es del todo irregular y reviste un carácter intrusivo. Uno de los datos más tempranos para pipas con hornillo se refiere al Complejo San Francisco (Selvas Occidentales del noroeste argentino). Al respecto, Dougherty agrega que en esa zona las pipas alcanzan una gran abundancia y que, además de pipas con base de apoyo (modalidad que parecería ser común hacia el sur de la región sanfranciscana), existen ejemplares con patas; la decoración de los hornillos es bastante frecuente y consiste, por lo general, en modelados y aplicaciones que conforman motivos ornitomorfos y zoomorfos. Para el Complejo San Francisco se tiene una fecha de 620 a.C. Una primera diversificación del modelo original, arguye Dougherty, podría hallarse en los ejemplares de Tebenquiche y de Laguna Blanca (en la puna); modificaciones mayores las encontramos entre las pipas de Ciénaga, mientras que Condorhuasi parecería conservar la mayoría de los rasgos sanfranciscanos.

En general, las pipas con hornillo aparecen como un elemento recurrente en las fases formativas de todas las culturas del noroeste argentino hasta aproximadamente 300 d.C. Raffino (1977), al referirse a las pipas encontradas en las aldeas del Formativo Inferior de la Quebrada del Toro (Salta), dice que estas se caracterizan por la ejecución del hornillo en forma cilíndrica y no infundibuliforme, una variante que, dentro del Formativo, muestra diferencias regionales como en los rodetes anulares aplicados para fortalecer la unión entre ambas ramas; la decoración de las pipas de Quebrada del Toro ha sido ejecutada por técnica de incisión grabada, pintada y pastillaje sobre la rama vertical y el hornillo; los motivos son geométricos, lineales $\mathrm{y}$ puntiformes.

Krapovickas (1955) clasifica en cuatro grupos las pipas con hornillo, incluyendo en el cuarto grupo aquellas halladas en la puna de Salta (Tebenquiche). En estas últimas, el hornillo se forma a expensas de la rama ascendente, la que se ensancha en su altura media, no habiendo una diferencia tan marcada entre la rama horizontal y la ascendente, como sucede en los otros grupos. En la base del ángulo se agregan dos patas planas o cónicas; la rama ascendente es muy larga y llega a sobrepasar la mitad de la extensión de la horizontal; presentan decoraciones con motivos incisos y en relieve junto al borde del hornillo. Este cuarto grupo tendría su centro en el norte, en 

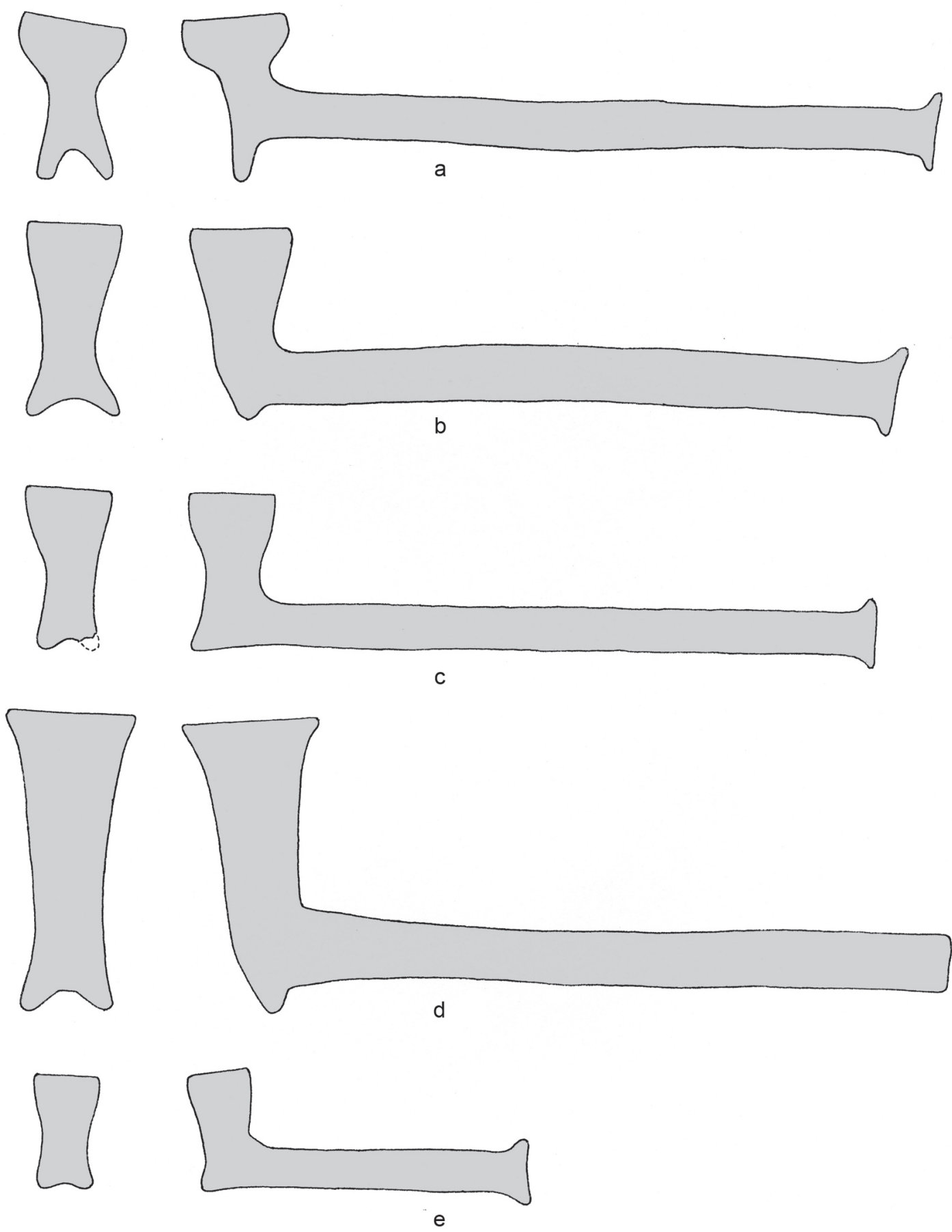

Figura 2. Pipas: (a) Toconao Oriente: 4646-48; (b) Toconao Oriente: 4317; (c) Séquitor: 1023-27; (d) Toconao Oriente: 4383bis; (e) Séquitor: sin número.

Pipes: (a) Toconao East: 4646-48; (b) Toconao East: 4317; (c) Séquitor: 1023-27; (d) Toconao East: 4383bis; (e) Séquitor: without number. 

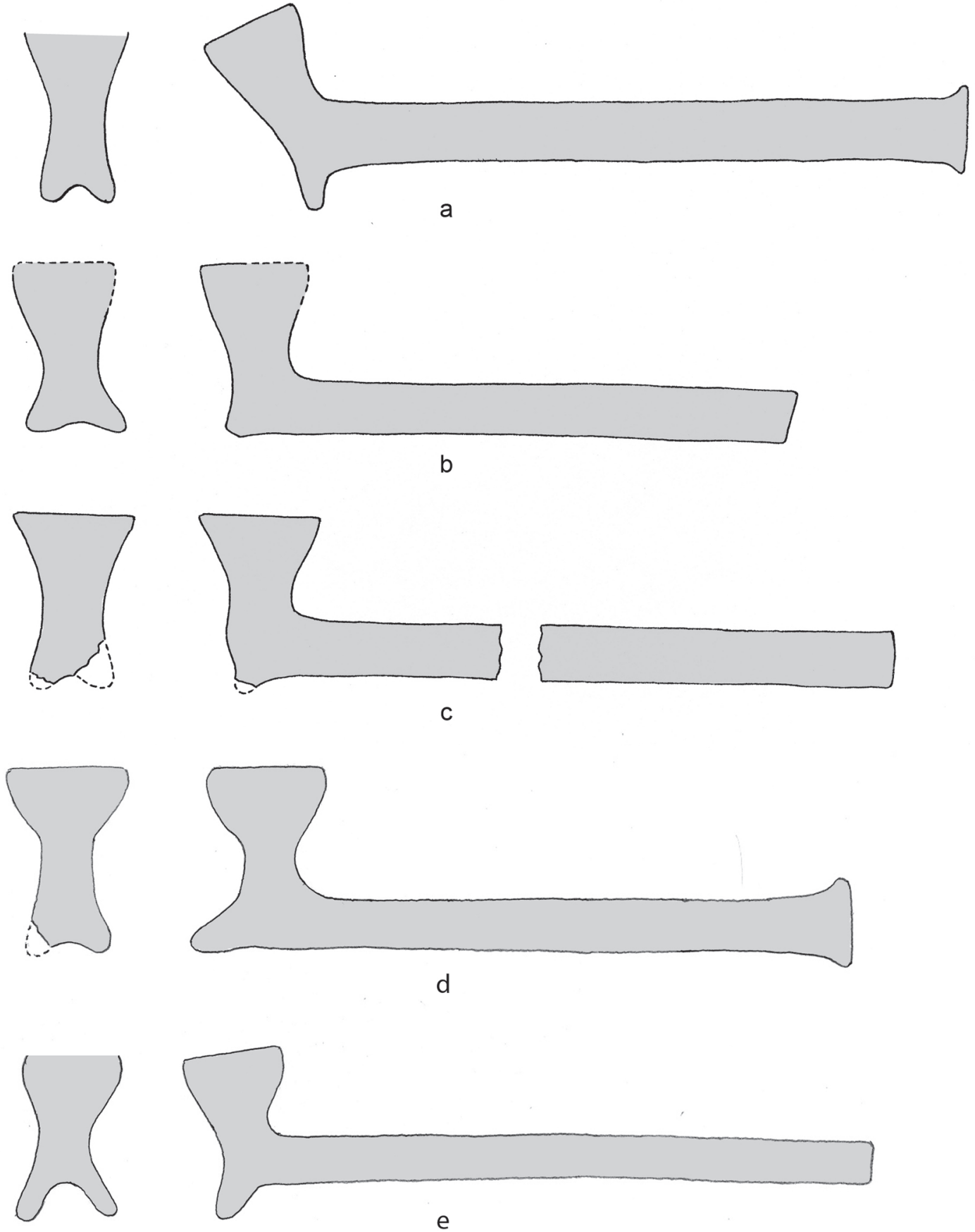

Figura 3. Pipas: (a) Séquitor: 1060-68; (b) Toconao Oriente: 4263; (c) Quitor 6: 2796-99; (d) Séquitor: sin número; (e) Larrache: sin número.

Pipes: (a) Séquitor: 1060-68; (b) Toconao East: 4263; (c) Quitor 6: 2796-99; (d) Séquitor: without number; (e) Larrache: without number. 

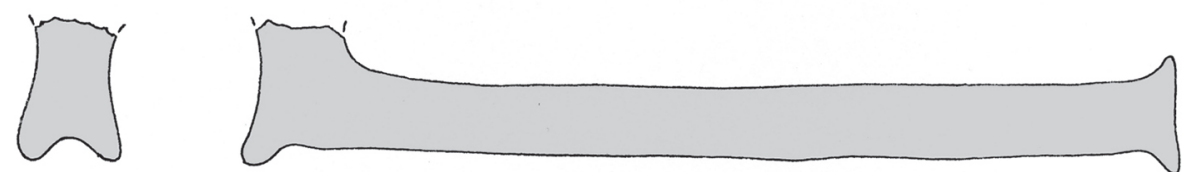

a
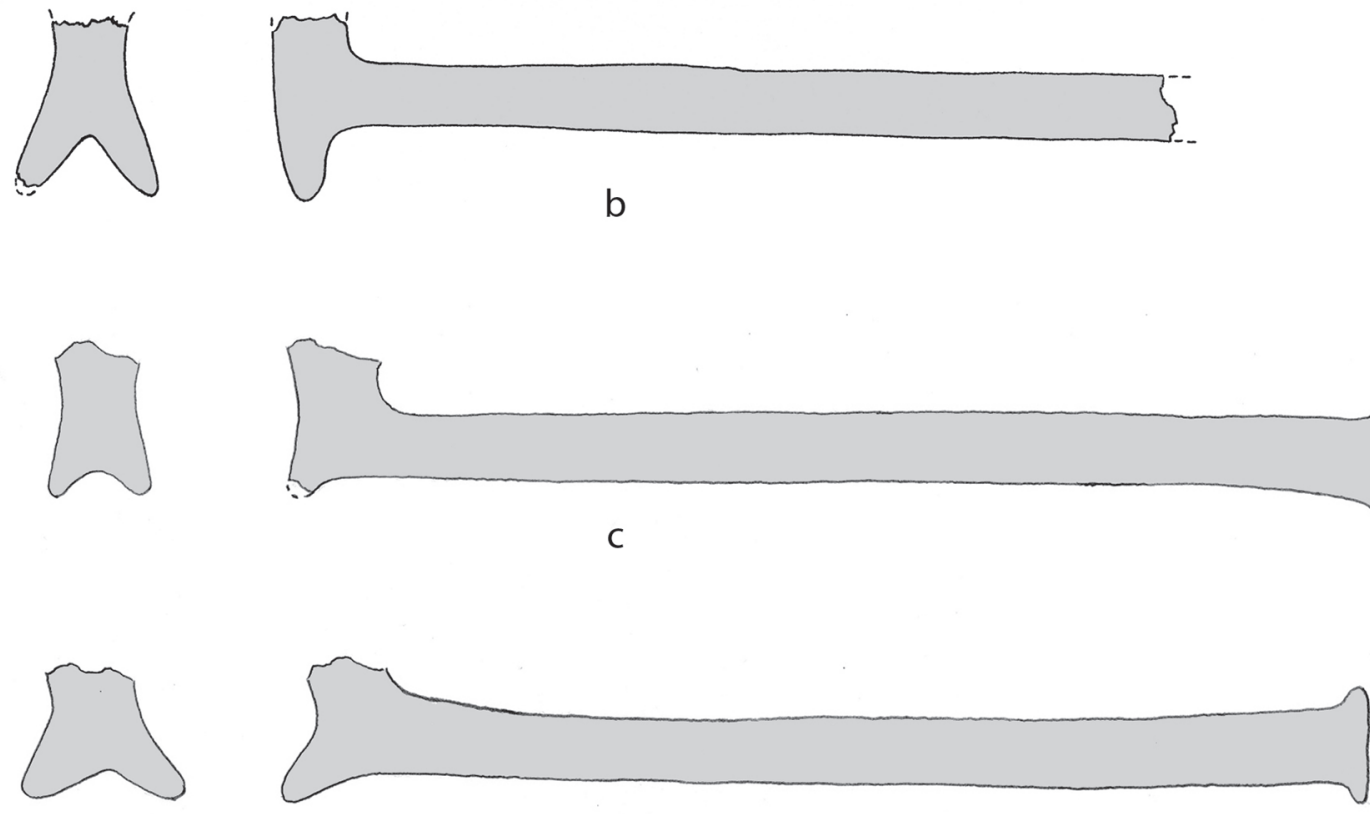

d
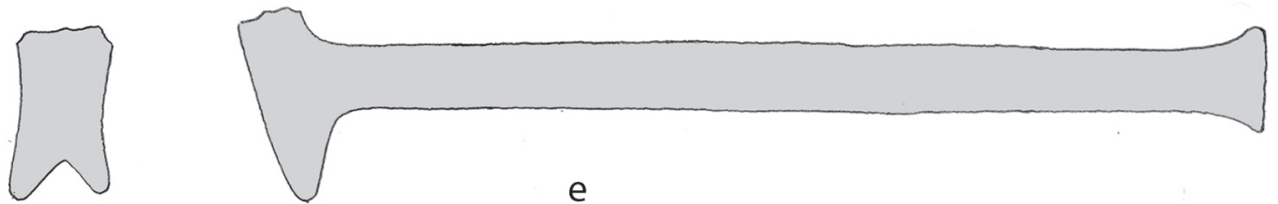

Figura 4. Pipas: (a) Solor: 951; (b) Toconao Oriente: 4203-05-05bis; (c) Quitor 6: 2639-40; (d) Toconao Oriente: 4708-09; (e) Larrache: 1715.

Pipes: (a) Solor: 951; (b) Toconao Oriente: 4203-05-05bis; (c) Quitor 6: 2639-40; (d) Toconao Oriente: 4708-09; (e) Larrache: 1715.

los valles calchaquíes. Krapovickas (1977) estudió otro sitio en la puna de Jujuy (cerro Colorado), donde encontró solamente fragmentos de pipas, la mayoría de los cuales tiene superficies rojizas. Uno de estos fragmentos sugiere que estas pipas debieron tener patas o proyecciones y que el ángulo formado por la rama vertical y horizontal debió ser agudo en lugar de recto, lo que le da cierto parecido con las pipas de la cultura Condorhuasi.
Como casos excepcionales en SPA se registran un caso de pipa tipo "monitor" (Figura 5e) y un caso de pipa en forma de $\mathrm{T}$ invertida (Figura 5f). Las primeras, según el citado mapa de Boman, se distribuirían en el sur de Chile y sur de Argentina; en tanto las segundas son citadas especialmente como asociadas al complejo formativo El Molle del norte-centro chileno y, hacia el sur, se las describe hasta el seno de Reloncaví (Westfall 1993-94). 

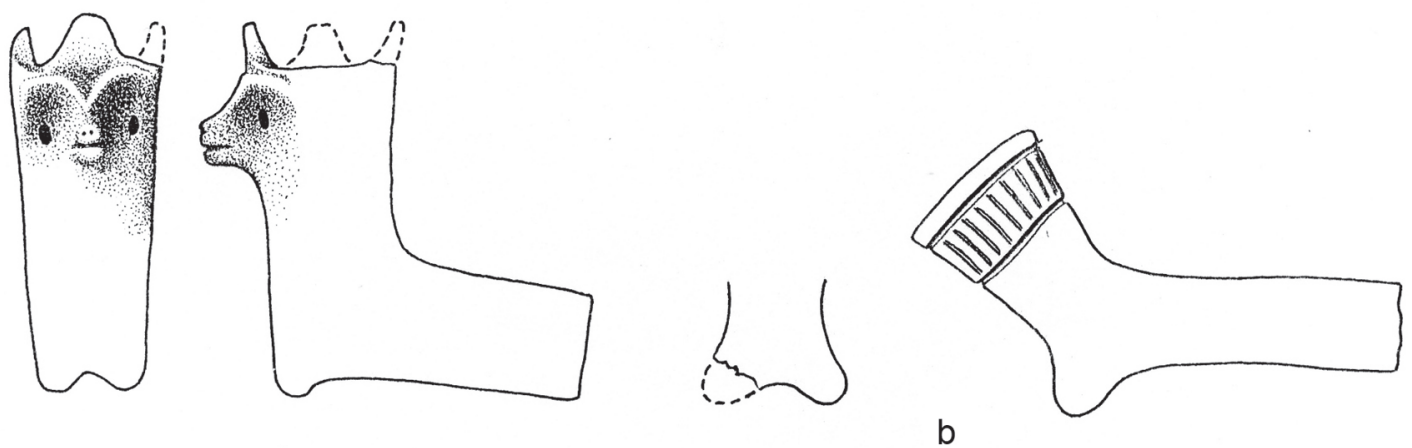

a

b
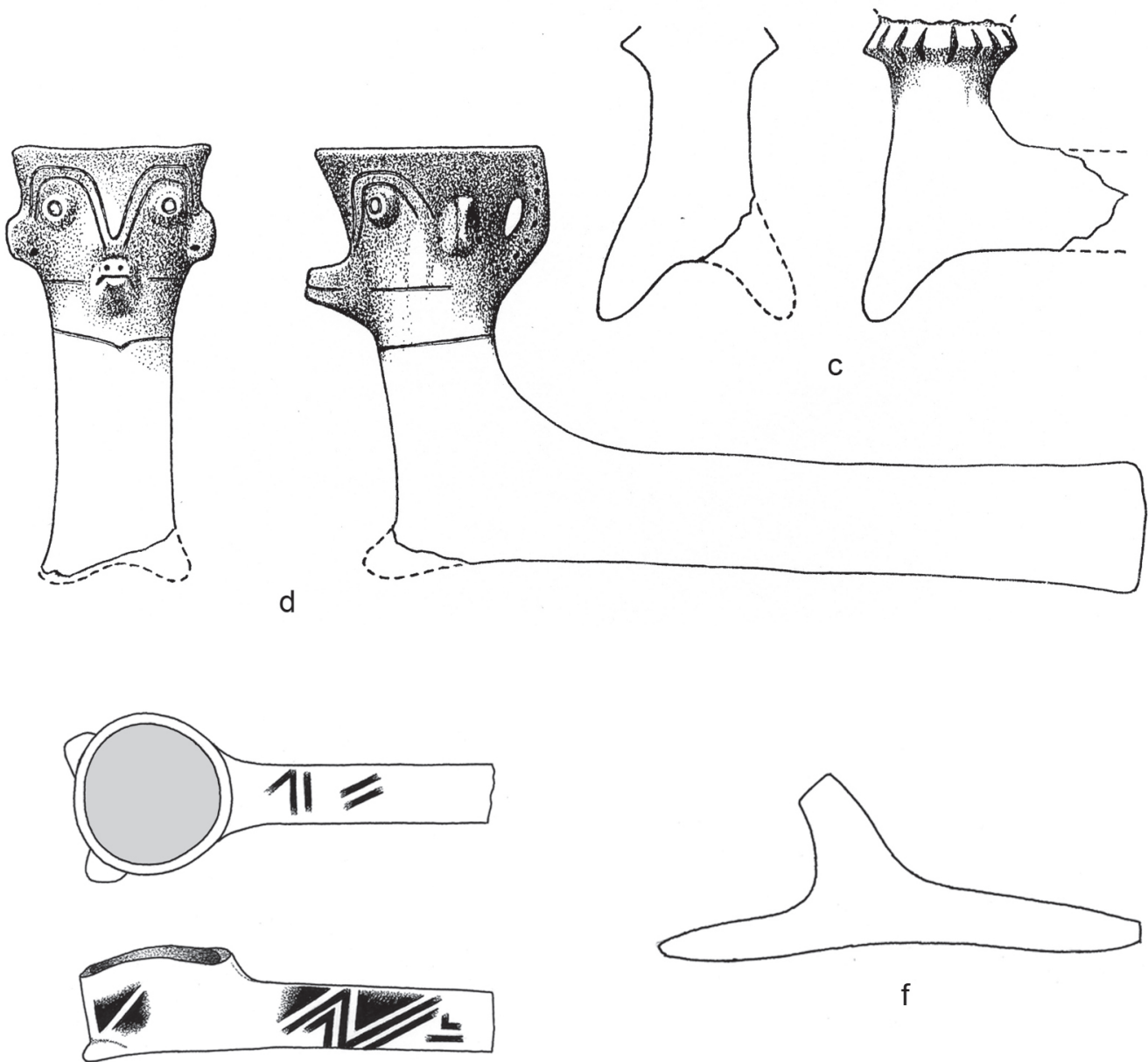

e

Figura 5. Pipas con hornillo decorado: (a) Tchaputchayna: 3821; (b) Séquitor: 1075-80; (c) sin registro; (d) Toconao Oriente: 4635. Pipa monitor: (e) Séquitor: 947. Pipa en forma de T invertida: (f) Séquitor: 1060-68.

Pipes with decorated burner: (a) Tchaputchayna: 3821; (b) Séquitor: 1075-80; (c) without register; (d) Toconao East: 4635. Monitor pipe: (e) Séquitor: 947. Inverted T-shape pipe: (f) Séquitor: 1060-68. 
En la cuestión de tabletas tempranas, tanto para la región circumpuneña como para SPA, el registro arqueológico no ha sido tan generoso como con las pipas, indudablemente por lo deleznable de la madera, materia prima comúnmente utilizada para la confección de este tipo de objetos. Las referencias de mayor antigüedad para tabletas las tenemos lejos de nuestro territorio, en la costa peruana (Huaca Prieta), lugar desde donde Bird y Hyslop (1985) reportan el hallazgo de una tableta rectangular y de un tubo de hueso de ave con una fecha de 1.200 a.C. Más al sur, los únicos hallazgos de tabletas tempranas se refieren al complejo Faldas del Morro, en Arica, complejo al que se le asigna una antigüedad entre 300 a.C. a 300 d.C. (Núñez 1969).

Uhle sostenía, en 1915, que hasta entonces no se conocían para el norte de Chile tabletas de origen más antiguo que las de la civilización de Tiwanaku, pero que el uso de los tubos sería mucho más antiguo. Esta posición la mantuvo en trabajos posteriores. Hasta su época, las tabletas encontradas en el norte de Chile no habían sido de los mejores ejemplares; eso le hizo afirmar que "los buenos trabajos de esta clase deben, por lo general, atribuirse a importaciones de la región diaguita [Argentina]..., y que los trabajos menos finos representan en su mayor parte productos locales" (Uhle 1915:134).

Núñez (1963) mantuvo el planteamiento de Uhle, de que no habían tabletas de origen más antiguo que Tiwanaku, pero acota que, así como se observan tabletas vinculadas a Tiwanaku por sus atributos labrados con claridad indiscutida, también se observan algunas con decoraciones que no concuerdan con influencias de esa cultura, y otras, que simplemente no llevan decoraciones. Para explicar esta situación, el investigador dice que en la misma medida que se registran junto a influencias "foráneas" manufacturas de uso o de tradición local, son estas tabletas productos de creaciones localistas, coexistentes con la hechura de tabletas bajo patrones adquiridos, o posteriores en el tiempo, conservando la tradición formal anterior y variándose la decoración por nuevos temas más tardíos. Piensa entonces que aquellas tabletas diferentes a las tiwanaku responden a variaciones locales posteriores a los contactos con la cultura tiwanaku. Le Paige fue el primero en cuestionar el supuesto origen altiplánico de las tabletas para alucinógenos al dejar planteada la pregunta "¿hay que mantener que su origen es tiahuanacoide?" (Le Paige 1963:14).

\section{Referencias para San Pedro de Atacama}

En relación con las pipas en San Pedro de Atacama, Le Paige (1963), en su propuesta de una sucesión de siete niveles para el período agroalferero, señala que el Nivel 1 (más antiguo) se caracteriza por la presencia de cerámica roja pulida y negra antropomorfa de gollete cónico y "pipas de greda largas". Por su parte, Tarragó (1989) consigna la aparición de las pipas para la segunda de las ocho fases que ella establece para la localidad-fase Toconao (300 a.C. a 100 d.C.)-, señalando que estos artefactos continúan en la fase Séquitor (100 d.C. a 400 d.C.) y desaparecen en la fase Quitor (400 d.C. a 700 d.C.). Por su parte, Gili (2014) realiza un análisis de la colección de pipas del Museo de San Pedro de Atacama y aporta nueva información sobre estos artefactos. En cuanto a dataciones absolutas, se dispone de tres fechas TL para tumbas de Toconao Oriente asociadas con pipas: 120 d.C. (tumba 4646-48), 230 d.C. (tumba 4263) y 310 d.C. (tumba 4383bis) (Berenguer et al. 1986); además, dos fechas radiocarbónicas para una tumba múltiple de Séquitor Alambrado (1060-68): 422-602 d.C. y 256-544 d.C. (Hubbe et al. 2011).

Al contrario de las pipas, las tabletas han acaparado mayormente la atención de los estudiosos $\mathrm{y}$, en consecuencia, se registra una mayor referencia bibliográfica sobre el tema. Thomas y Benavente (1984) señalan que algunos grupos de tabletas, especialmente de receptáculos rectangulares y paneles trapezoidales con motivos grabados e incisos y con mangos con motivos zoomorfos y antropomorfos de dos, tres o cuatro individuos, podrían ser reputados al contacto Tiwanaku; en cambio, algunas formas simplificadas (antropomorfas o zoomorfas) podrían pensarse que son anteriores a las mencionadas. En otro trabajo de los mismos autores, a los que se agrega Massone, lo único claro que se desprende en relación con el análisis cronológico de momentos tempranos de las tabletas es que ellas, durante un momento más temprano, aparecen con clara correspondencia a formas cerámicas, primero un subgrupo con decoraciones geométricas modeladas, luego un subgrupo con decoraciones geométricas talladas y finalmente un subgrupo cuya decoración está dada por una horadación esférica. Este último subgrupo revela una mayor duración en el tiempo llegando probablemente hasta cerca del 700 d.C. (Thomas et al. 1984). 
Tarragó (1985) atribuye dos tabletas a la fase Toconao (300 a.C. 100 d.C.): un caso fuera de modalidad asociada a una pipa (tumba 1947 de Quitor 5) y otro caso con decoración geométrica rectilínea que puede ser del final de la fase Toconao o de comienzos de la fase Séquitor (tumba 2225-26 de Quitor 5). Para la fase Séquitor (100 d.C. a 400 d.C.) la autora dice que es clara la coexistencia de dos formas de consumo de alucinógenos: en pipa y en tabletas.

La primera investigación contextual que involucró diferenciación cronológica del complejo psicotrópico fue realizada por Llagostera et al. (1988), quienes se ocuparon de las tabletas y tubos de Solcor 3 , analizando sus iconografías, sus asociaciones y sus secuencias, conjuntamente con su relación respecto de las características antropofísicas de los restos humanos. Para el mencionado sitio se definió una fase inmediatamente pre-Tiwanaku que se inserta en un rango cronológico de 250 a 450 años d.C. y otra, con evidentes influencias de la cultura altiplánica, desde 450 a, por lo menos, 650 años d.C. Este trabajo reveló definitivamente la existencia de tabletas anteriores a la época de influencia Tiwanaku, planteamiento que ha sido reforzado por una fecha obtenida por nosotros de 190+100 d.C. (UCTL-224) para una tableta de Toconao Oriente (tumba 4229-30, Figura 6c), siendo esta la fecha más temprana hasta el momento para tabletas de San Pedro de Atacama.

Torres et al. (1991) dicen que el hallazgo de bufotenina en las muestras de sustancias asociadas con tabletas en SPA sugiere que la fuente de este material era una especie vegetal del género Anadenanthera. Para las pipas podría haber sido el mismo alucinógeno además de otro no identificado. Fernández Distel (1980) señala que el análisis químico del contenido de las pipas de Inca Cueva

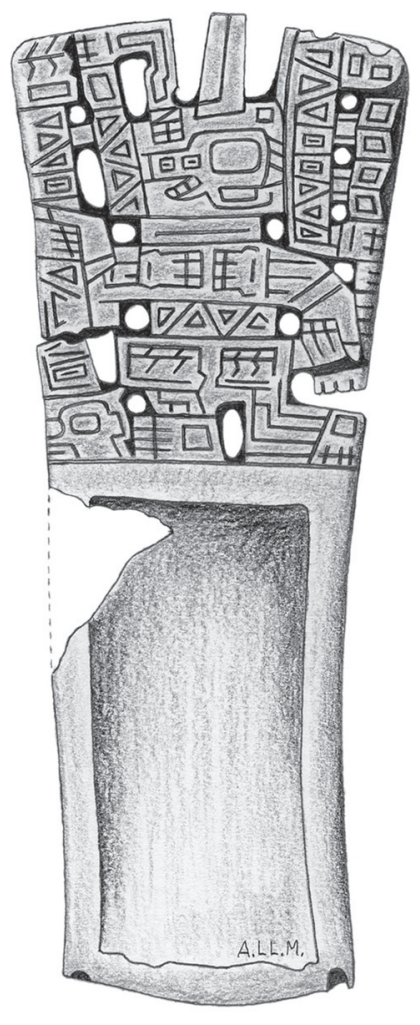

a

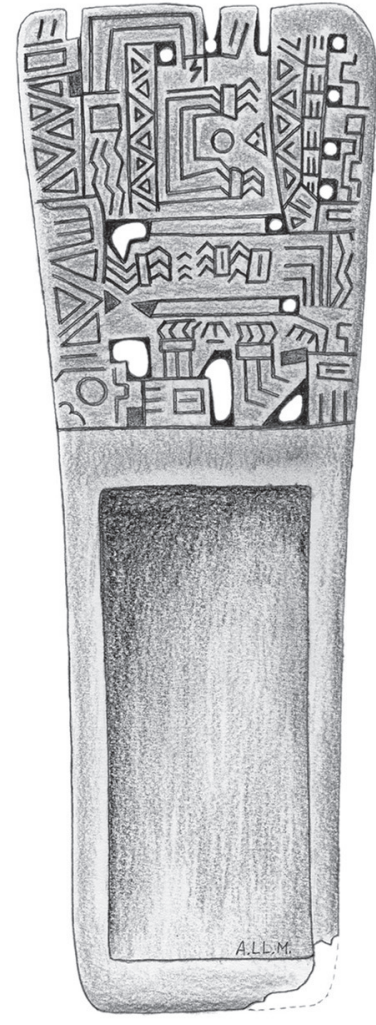

b

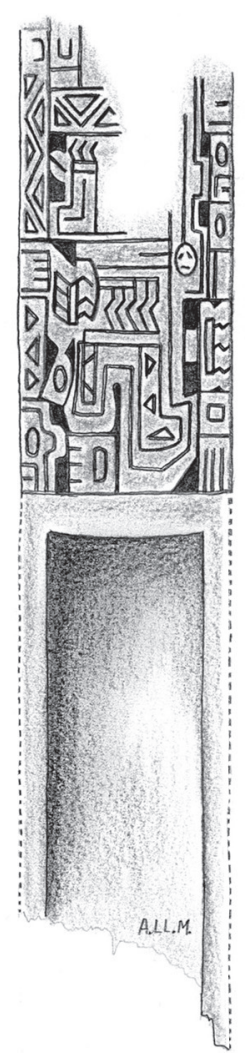

C

Figura 6. Tabletas con representación de personajes genuflexos en vista lateral: (a) Quitor 8: 3229-30; (b) Quitor 5: 3380; (c) Toconao Oriente: 4229-30.

Tablets with depictions of a kneeling figures in lateral sight: (a) Quitor 8: 3229-30; (b) Quitor 5: 3380; (c) Toconao East: 4229-30. 
(noroeste argentino) indicó la presencia de un alcaloide con igual conducta y características que la N,N dimethyltryptamina, componente activo de la bufotenina, la que a su vez es el alcaloide de la Anadenanthera; en cambio, para las pipas de Huachichocana se obtuvo una reacción altamente positiva a los alcaloides, pero negativa para aquel compuesto, "por ello debemos descartar que se haya fumado el Cebil" (Fernández Distel 1980:65). Rosso y Spano (2005/06), por análisis en contenidos de pipas del valle Calchaquí (Campo Colorado y Sonia 2), asumen que en ellas se utilizó Anadenanthera.

En relación con fragmentos de pipas encontrados en la quebrada de Tulán, Núñez et al. (2009) asumen que en ellas se fumó Anadenanthera, ya que los análisis efectuados en artefactos de molienda detectaron residuos de este vegetal (McRostie 2010). En cuanto a análisis químicos efectuados directamente en residuos de pipas de San Pedro de Atacama, Gili (2014) señala que estos han dado resultados negativos para alcaloides pertenecientes a Anadenanthera, así como también escasas evidencias de Nicotiana. La autora, entre las posibles causales de esta ausencia, hace referencia a la volatilización de los alcaloides (Gili 2014:120). En consecuencia, consideramos que la posibilidad de que se haya utilizado Anadenanthera todavía no puede ser descartada, ya que sabemos que las moléculas de estos alcaloides son extremadamente lábiles, por lo cual podrían haberse alterado en el proceso de combustión.

\section{Ámbito Cronológico}

El ámbito de nuestro problema es la emergencia de pipas y tabletas en San Pedro de Atacama lo que, de acuerdo a los antecedentes presentados, nos proyecta a las fases tempranas del período agroalfarero. Para poder identificar los ejemplares de data temprana, además de las fechaciones existentes, utilizamos como apoyo referencial preferentemente la información entregada por los contextos asociados, concretamente la alfarería Roja Pulida y sus acompañantes, las cuales han sido reconocidas como propia de las fases tempranas del período Agroalfarero de San Pedro de Atacama (Le Paige 1963; Orellana 1963, 1991; Tarragó 1968).

En consecuencia, consignaremos como materia de este análisis aquellos artefactos asociados con alfarería Roja Pulida y, por extensión, otras formas alfareras diagnósticas de contextos tempranos. Por un lado esta alfarería nos estaría enmarcando en un lapso de tiempo que va desde 170 a.C. hasta 240 d.C. (Berenguer et al. 1986). Por otro lado, entre la alfarería que Tarragó (1989) señala como asociada con la cerámica Roja Pulida, destacan tres tipos de Negra Pulida temprana claramente identificables por su forma: (a) tazones troncocónicos de base plana, con dos asas horizontales de inserción oblicua; (b) jarros cilíndricos de base plana con un asa vertical y; (c) jarros de contorno hiperboloide de base plana y un asa vertical. En el muestreo realizado por Berenguer et al. (1986), el primer tipo aparece con fechas entre 170 a.C. y 140 d.C.; a ellas, nosotros agregamos dos fechas TL de $245 \pm 170$ d.C. (UCTL 856 ) y $255 \pm 170$ d.C. (UCTL 859). Para el segundo tipo, los autores precedentes dan fechas de $80 \pm 200$ y $90 \pm 200$ d.C., a las cuales nosotros añadimos una de $55 \pm 190$ d.C. (UCTL 858). Para el tercer tipo hemos obtenido fechas de $120 \pm 180$ d.C. (UCTL 857 ) y $285 \pm 150$ d.C. (UCTL 855). En consecuencia, utilizando como indicadores cronológicos estos tipos diagnósticos de alfarería es posible segregar tabletas y sus contextos en un rango de tiempo entre 170 a.C. y 285 d.C., lo que asegura el carácter temprano de los ejemplares asociados.

\section{Pipas}

En las colecciones del Museo de San Pedro de Atacama se consignan 58 registros de pipas procedentes de Toconao Oriente, Séquitor Alambrado (Oriente y Acequia), Quitor 5 y 6, Solor, Tchapuchayna, Larrache, Tulor (Algarrobo y Pueblo), Beter, Poconche, Coyo, y Coyo Aldea (Gili 2014). En este conjunto se involucran tanto artefactos completos como fragmentos, ya sea con registro de procedencia o sin esta información. El tipo predominante es el de pipas con hornillo (Figuras 2, 3, 4 y 5); a ellas se suma una de tipo monitor y una en forma de $\mathrm{T}$ invertida.

De las 58 referencias a pipas solo 26 son asignables a contextos conocidos y se distribuyen en los cementerios de Larrache (tumba 1715), Quitor 2 (1254-57), Quitor 5 (1947), Quitor 6 (2522-23, 263940 y 2796-99), Séquitor Alambrado (947, 1023-27, 1052-59, 1060-68, 1075-80, 1627), Solor (951, 1041), Tchaputchayna (3821) y Toconao (4203-05-05bis, 4263, 4317, 4372, 4380-81, 4383bis, 4393-94, 4635, 4646-48, 4665-69 y 4708-09) (Figuras 2, 3, 4 y 5).

Todos estos casos hacen parte del ajuar funerario de 12 tumbas individuales (incluyendo una de un 
niño), cinco tumbas dobles (cuatro de adultos y una de un adulto y un niño) y nueve tumbas de tres a ocho individuos (las que incluyen solo adultos o combinación de adultos con jóvenes, niños y fetos). Para efectos de la valoración contextual de nuestro análisis consideraremos solamente las tumbas individuales y dobles; las de más de dos individuos, solo en los casos en que los contextos no presenten mezcla de períodos.

Bajo este criterio se ha seleccionado 18 tumbas de las cuales cinco presentan en sus contextos alfarería Roja Pulida y Negra Pulida temprana (Toconao: 4372, 4393-94, 4635, 4646-48 y 4708-09), cinco con Negra Pulida intermedia (Quitor 6: 2639-40 y 2796-99, Séquitor Alambrado:1627, Toconao: 4263 y 4317), seis con alfarería Negra Pulida clásica (Quitor 2: 1254-57, Quitor 6: 2522-23, Séquitor Alambrado: 947, Solor 3: 951, Toconao: 4383bis y 4665-69); dos con negra "casi" pulida y asociadas (Tchaputchayna: 3821, Solor 1041).

De acuerdo con esto, el primer grupo puede ser considerado como de la fase Toconao con cinco ejemplares, el segundo grupo a la fase Séquitor con cinco, el tercer grupo a la fase Quitor con seis ejemplares y el cuarto grupo a la fase Coyo con dos. Comparando directamente con contextos portadores de pipas, tenemos disponible fecha TL para el sitio Toconao correspondientes a la fase Toconao: 120 d.C. (4646-48), a la fase Séquitor 230 d.C. (4263) y a la fase Quitor 310 d.C. (4383bis) (Berenguer et al. 1986). El problema con las fechas de la tumba 1060-68 de Séquitor (422-602 d.C. y 256-544 d.C.) (Hubbe et al. 2011) es que se trata de una tumba múltiple con mezcla de contextos, por consiguiente no se sabe a cuál de los individuos es asignable la pipa.

Como se señaló anteriormente, la generalidad de las pipas se ajusta al formato de pipas con hornillo vertical; sin embargo, algunas de ellas resultan excepcionales, ya sea por tratarse de pipa monitor como la de Séquitor (947), por su forma de T invertida como otro ejemplar de Séquitor (1060-68) o por poseer el hornillo decorado como las de Tchaputchayna (3821), Toconao (4635) y, también, Séquitor (1075-80) (Figura 5). No deja de ser interesante el hecho de que Séquitor concentra casi todas las pipas atípicas presentes en San Pedro de Atacama y que estas representan prácticamente el $50 \%$ de su complejo fumitorio, lo que sin duda se relaciona con la esfera de vinculación transandina que tuvo este sitio.
Los portadores de pipas en tumbas individuales son siempre hombres, lo que define a estos artefactos como implementos de uso masculino. Hay un caso de un niño, el que, en consecuencia, debería asumirse como masculino. De las 20 tumbas seleccionadas, 15 se asocian con algún objeto relevante. Entre este tipo de objetos se registran: cuatro casos con hacha, cuatro con mazo, dos con objetos de cobre y cinco con tabletas para alucinógenos. El contexto alfarero para las tumbas individuales con pipas da un promedio de 6,8 piezas cerámicas por tumba, con extremas entre 1 y 13 .

\section{Tabletas Tempranas}

Por la resistencia de la cerámica tenemos la seguridad de que las pipas registradas representan el total de ejemplares que fueron depositadas en los cementerios excavados. No sucede lo mismo con las tabletas, ya que un número considerable de ellas debe haberse desintegrado en las tumbas por las condiciones del terreno, lo que muchas veces no fue favorable para la conservación de la madera. Si bien el total de tabletas que registra la colección Le Paige es de aproximadamente 465 ejemplares, solo siete de ellos se pueden consignar con seguridad a fases tempranas, atendiendo a las asociaciones alfareras que las acompañan. Estas tabletas han sido recuperadas de los cementerios Quitor 5 (3380), Quitor 8 (3156, 3178, 3187, 322930 y 3231) y Toconao Oriente (4229-30) (Figuras 6 y 7$)^{1}$, y se encuentran distribuidas en cinco tumbas individuales y en dos tumbas dobles (todas contienen solamente adultos).

Entre esas tabletas hay una que se asocia con alfarería Roja Pulida (Quitor 8: 3187), dos con alfarería Negra Pulida temprana (Quitor 5: 3380, Quitor 8: 3178), y cuatro con alfarería Roja Pulida y Negra Pulida temprana (Quitor 8: 3156, 322930, 3231, Toconao: 4229-30). Todo este conjunto se afiliaría a la fase Toconao. Para los casos correspondientes a Toconao Oriente tenemos fechas TL de 190 d.C. (4229-30) (Berenguer et al. 1986).

En la iconografía de las tabletas tempranas destacan aquellas de Quitor 5 (3380) y Quitor 8 (3229-30) las cuales representan un personaje de perfil, genuflexo, orientado hacia el lado derecho, mirando hacia arriba y con una prominente nariz; luce un complejo tocado en su cabeza y un cetro en su mano derecha, aditamento que termina en su extremo superior en un elemento tridígito y por 


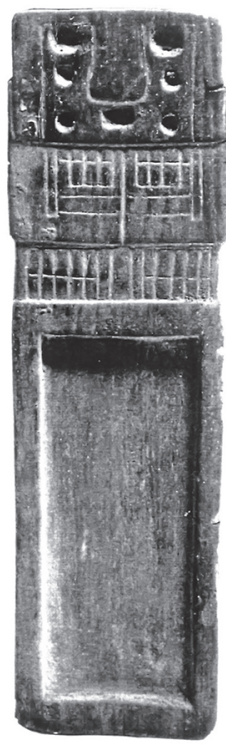

a

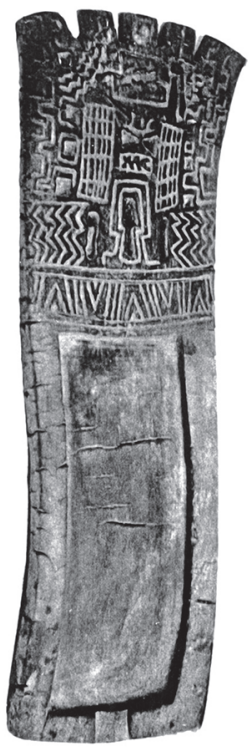

b

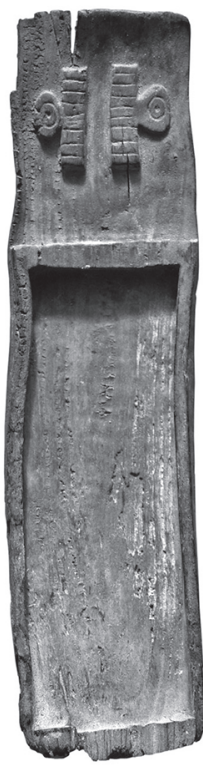

$\mathrm{C}$

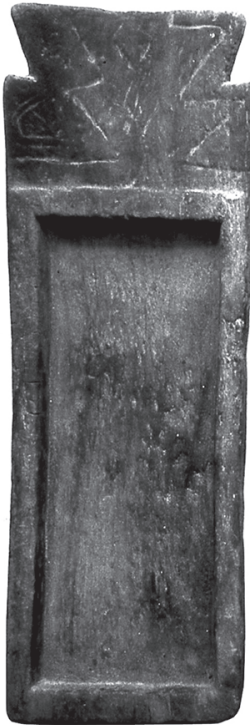

d

Figura 7. Tabletas tempranas de Quitor 8: (a) 3187; (b) 3156; (c) 3178; (d) Quitor 5: 1947. Figuras (a) y (b) gentileza de M. Tarragó. Early tablets of Quitor 8: (a) 3187; (b) 3156; (c) 3178; (d) Quitor 5: 1947. Figures (a) and (b) courtesy of M. Tarragó.

el inferior en una cabeza trofeo. De su boca, con afilados dientes, emerge una proyección que también termina en el elemento de tres dígitos y su ojo está contorneado por un adorno orbicular; el elemento decorativo que más se reitera son líneas en zigzag con triángulos alternadamente contrapuestos. Este personaje ha sido diseñado en el panel de la tableta combinando técnicas de calado y grabado (Figuras 6a y 6b). Un ejemplar de Toconao Oriente (422930) se inscribe en el mismo patrón de personaje genuflexo, pero, debido al deterioro de la parte superior del panel no es posible conocer los detalles de su cabeza (Figura 6c).

Otras figuras de compleja iconografía corresponden a los ejemplares 3187 y 3156 , ambos de Quitor 8. El primero es un personaje antropomorfo sobre panel plano, en posición frontal, elaborado en un estilo cubista muy simple: con tres rectángulos superpuestos se ha representado la cabeza, el tronco y las extremidades inferiores y, con un mínimo de trazos se ha esbozado en ellos el rostro, las manos y los pies (Figura 7a). La otra presenta una compleja composición a base de dibujos geométricos en la que se combinan retículos, líneas paralelas zigzagueantes, triángulos alternados con líneas rectas paralelas, líneas quebradas en ángulos rectos y otras lineaturas difíciles de describir (Figura 7b). En el mismo sitio, pero contrastando con la complejidad de las anteriores, se hace presente un ejemplar que destaca por su simplicidad: sobre el panel plano se ha diseñado dos cortos cilindros longitudinales segmentados, cada uno de ellos con un apéndice subcircular a su costado externo y tres líneas incisas que se proyectan hacia el borde superior (3178) (Figura 7c).

Dado que nos interesa conocer la relación entre la tradición de pipas y la de tabletas en San Pedro de Atacama, consideraremos también la información entregada por las tumbas en las que se encuentran asociaciones entre estos dos artefactos (Figura 8). Estas las encontramos en Quitor 5 (1947), Quitor 6 (2522-23 y 2639-40), Séquitor Alambrado (947), Toconao (4383bis y 4665-69) (Figuras 7d y 9)2. Una de ellas se adscribiría a la fase Séquitor (Quitor 6: 2639-40) y el resto a la fase Quitor.

Estas seis tabletas son absolutamente disímiles entre sí; los formatos, los motivos, los estilos y las técnicas difieren notoriamente entre ellas. $\mathrm{La}$ tableta de Quitor 5 (1947) presenta escotaduras angulares a cada lado de los vértices del panel y líneas zigzagueantes grabadas en la superficie frontal de este (Figura 7d). Los ejemplares de Toconao, aun siendo ambas volumétricas, son muy diferentes: el ejemplar 4665-69 presenta cuatro 
figuras antropomorfas naturalistas, las que se yerguen sobre el borde superior de la tableta con sus manos de tres dedos apoyadas sobre el vientre y piernas semiflexionadas, también con tres dedos en cada pie (Figura 9a); en tanto, la tableta 4383bis representa un felino moteado posado sobre lo que sería el panel del artefacto (Figura 9b). Por su parte, uno de los ejemplares de Quitor 6 (2522-23) presenta en el borde superior del amplio panel carente de decoración, dos figuras zoomorfas tridimensionales con cuerpos enfrentados y cabezas mirando hacia el frente (Figura 9c). El otro ejemplar (2639-40), parece corresponder a una figura antropomorfa en posición frontal, a la cual le falta la cabeza y manos; en ella se combinan técnicas de calado y de grabado (Figura 9d). La tableta de Séquitor (947), por su deterioro, no permite reconocer su iconografía.

Ya se ha señalado que las tabletas son implementos asociados con individuos masculinos (Llagostera et al. 1988), no habiendo excepción en el caso de las tabletas tempranas. De las 12 tumbas con tabletas consideradas en este acápite, tres presentan en su ajuar dos objetos relevantes, cuatro con uno y dos con ninguno. Entre este tipo

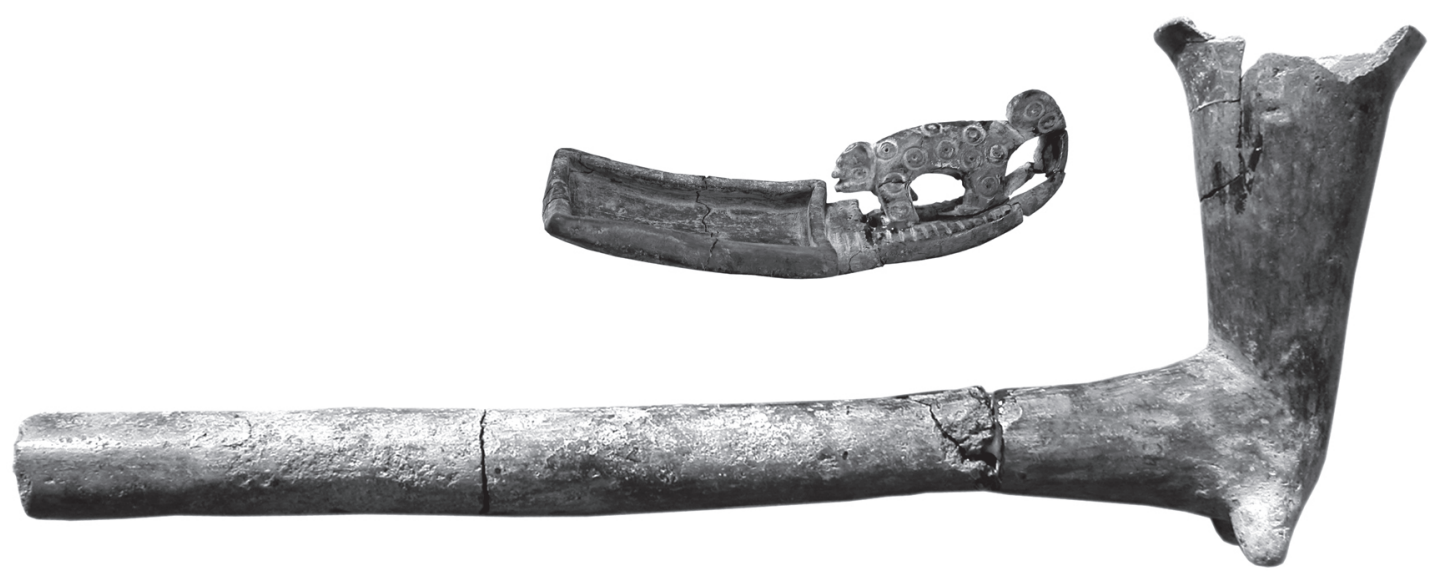

Figura 8. Pipa y tableta en una misma tumba: Toconao Oriente: 4383bis.

Pipe and tablet in the same tomb: Toconao East: 4383bis.

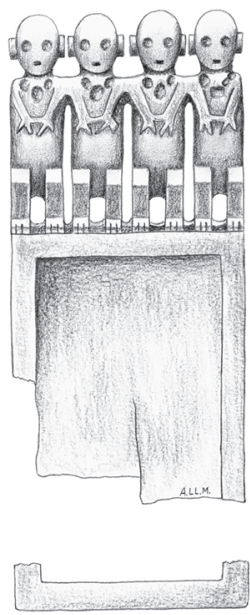

a
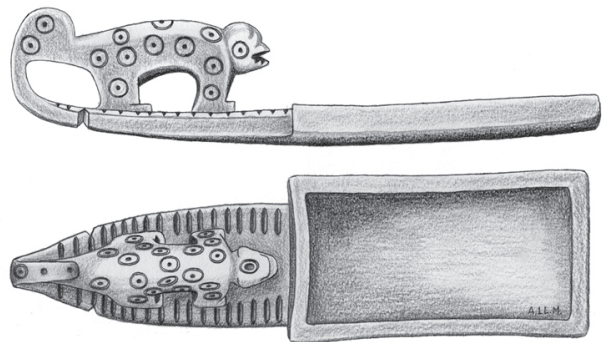

b

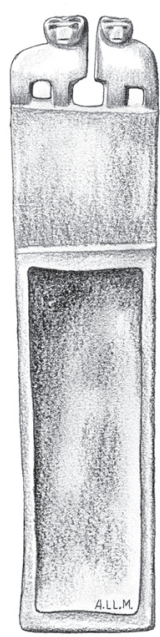

C

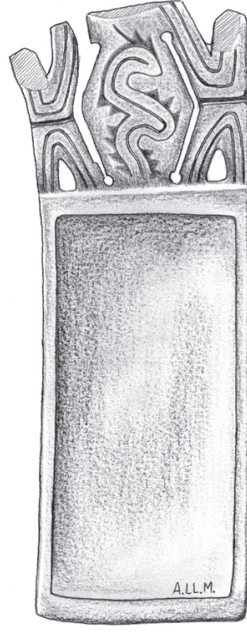

d

Figura 9. Tabletas asociadas con pipas: (a) Toconao Oriente: 4665-69; (b) Toconao Oriente: 4383bis; (c) Quitor 6: 2522-23; (d) Quitor 6: 2639-40.

Tablets associated with pipes: (a) Toconao East: 4665-69; (b) Toconao East: 4383bis; (c) Quitor 6: 2522-23; (d) Quitor 6: 2639-40. 
de objetos se cuenta, además de pipas: hacha de piedra, espátulas decoradas, objetos de cobre, tembetás y adorno probablemente de malaquita. Por su parte, los contextos alfareros de tumbas individuales arrojan un promedio de 6,3 piezas con extremos entre uno y 12 , siendo de resaltar que las que registran mayor número de vasijas son las que portan pipas en sus ajuares.

\section{Discusión}

Del análisis morfológico de las pipas resulta evidente que aquellas con hornillo son las predominantes en San Pedro de Atacama. En este último grupo prácticamente no es posible desarrollar una tipología, ya que cada una difiere de las otras en algún atributo: en la proporción y en el ángulo entre tubo y hornillo, la forma del hornillo, la forma del codo, el tamaño y la dirección de los podos, el tipo de decoración (cuando la tienen) y el color. Esta heterogeneidad parece ser la tónica imperante desde cualquier ángulo que se pretenda enfocar el análisis, situación que podría estar reflejando una diversidad de procedencias.

Tarragó (1989) señala que las pipas acodadas con patitas y boquilla de San Pedro de Atacama son similares a las de Campo Colorado (Salta), y que su baja ocurrencia y sus atributos de pasta y morfología indican que son foráneas y se relacionan con el noroeste argentino. Disentimos de Tarragó cuando postula que todas las pipas proceden de la zona de La Poma, expresamente de Campo Colorado, ya que la morfología de las pipas de San Pedro de Atacama plantea la posibilidad de otras procedencias, sin excluir Campo Colorado como una de ellas. En algunos casos es posible inferir la procedencia atendiendo a ciertas características; por ejemplo, aquellas de Tchaputchayna (3821) y Toconao (4635) de rostros zoomorfos en el frontis del hornillo tienen cierto parecido con las que han sido descritas para Tolombón y Seclanta, en Salta (Boman 1932: fig. 25 y 26). La pipa 4317 de Toconao, por su color anaranjado y sus inclusiones blancas, podría provenir de la zona de Yavi. El ejemplar monitor 947 de Séquitor, por su decoración, podría provenir del sureste de Bolivia (Tarija). A su vez, si usamos el descarte, no hay ninguna que coincida con las descripciones de Raffino (1977) para quebrada de El Toro; también, ninguna presenta un perfil distal agudo como las de cerro Colorado (Krapovickas 1977), así como tampoco decoración con motivos incisos del tipo de las de Tebenquiche (Krapovickas 1955). Entre las asociaciones contextuales laterales que podrían ser filogenéticamente diagnósticas para detectar interrelaciones, tenemos un tazón asociado a la pipa 1627 de Séquitor, del tipo que es reportado para Calahoyo, Yavi y Tarija (Fernández 1978; Krapovickas 1977 y von Rosen 1957).

Gili (2014), en referencia a análisis por fluorescencia de rayos X que se llevó a efecto en arcillas de pipas de San Pedro de Atacama, señala que fue posible segregar tres grupos de estos artefactos según sus pastas: (a) pastas originarias de la cuenca del salar (30\%); (b) pastas atribuibles a la zona del alto Loa (12\%) y; (c) pastas de origen no determinado (42\%). De acuerdo con estos porcentajes resulta que un monto significativo de pipas habría sido manufacturado fuera del ámbito del salar.

En cuanto a cronología, vemos que las pipas en San Pedro de Atacama hacen su aparición en la fase Toconao (300 a.C.-100 d.C.), proyectándose hasta la fase Quitor (400-700 d.C.), donde tenemos su mayor presencia. Hay dos casos en la fase Coyo (700-1000 d.C.), que consideramos atípicos, debido a que uno de ellos se trata de un fragmento (Solor 1041) y, el otro, un ejemplar con representación zoomorfa en el hornillo (Tchaputchayna: 3821, Figura 5a); formato que persistió por largo tiempo en el noroeste argentino pudiendo haber arribado excepcionalmente a San Pedro en aquellos tiempos. Dentro de la diversidad generalizada de las pipas no se observan atributos específicos y diferenciales que sean atribuibles a las diferentes fases en que ellas se hacen presentes.

Al contrastar los contextos de las tumbas que presentan pipas con la generalidad de los contextos funerarios de los correspondientes cementerios, se observa que sus portadores destacan por poseer ciertos elementos que los hacen parecer como de un estatus más destacado que el resto de los individuos allí inhumados. Es el caso de la posesión de hachas o mazos. Evaluando la presencia de estos implementos en cada uno de los sitios a los cuales pertenecen los portadores de pipas vemos que se trata de artefactos que solo unos pocos individuos poseen, por lo cual asumimos que pueden ser considerados como símbolos de jerarquía de mando, ya que a su vez, quienes portan hachas o mazos tienen contextos relevantes. Los portadores de hachas en Quitor 2 representan un 15,5\%, en Quitor 5 un 16,2\%, en Séquitor un 9,5\%; en tanto en Quitor 6, 14,2\% 
porta hacha y 5,2\% porta mazo; en Toconao solo hay portadores de mazos, representando el $1,4 \%$. Comparando estas cifras generales con el grupo de portadores de pipas vemos que de 26 tumbas, ocho tienen mazos o hachas, lo que da un $30,7 \%$. Este porcentaje prácticamente duplica el máximo de las cifras precedentes, dando a este grupo un sitial relevante dentro de la esfera de mayor jerarquía en sus correspondientes comunidades.

Como ya se ha resaltado, al igual que las pipas, la diversidad de formatos y técnicas de las tabletas tempranas da soporte para interpretarlas como elementos foráneos en San Pedro de Atacama. La iconografía de las tabletas de Quitor 5 (3380) y Quitor 8 (3229-30) recuerda a los personajes genuflexos de Tiwanaku, pero carecen de los atributos secundarios como las cabecitas de felino, falcónidas y peces, así como del pedestal, que proliferan en la ornamentación de las tabletas del período clásico de la entidad altiplánica (Llagostera 2006). La presencia de estos ejemplares en contextos de la fase Toconao las retrotrae en varios siglos en relación con el auge de Tiwanaku, situación que las haría coherentes en cronología e iconografía con las representaciones que se pueden apreciar en el dintel de calle Linares de La Paz, el que se asume como de las más tempranas representaciones Tiwanaku (Torres y Conklin 1995:99). En consecuencia, estas tabletas estarían llegando a San Pedro de Atacama desde algún centro altiplánico donde dicha iconografía estaba en vigencia con anterioridad a las expresiones clásicas de Tiwanaku.

Es en la fase Quitor cuando se registra la mayor coincidencia de pipas con tabletas, y esto corresponde a seis casos, los que se adscriben a las tumbas: 1947 de Quitor 5, 2522-23 y 2639-40 de Quitor 6, 947 de Séquitor Alambrado, 4383bis y 4665-69 de Toconao. Ellas corresponden a tres tumbas individuales, a una con dos adultos, a una con dos adultos y un niño y a una con cinco individuos. En los contextos donde ambos implementos se hacen presentes destaca la tumba 4383bis de Toconao Oriente, la que además de un disco y cuatro pendientes de cobre ("campanitas"), contiene una pipa y una tableta para alucinógenos, con su correspondiente tubo de cobre. Otra (Quitor 6, 2522-23) incluye un hacha de piedra. En el primer caso estaríamos frente a un personaje de estatus pero sin mazo ni hacha, lo que mostraría el prestigio del complejo psicotrópico aunque no necesariamente de mando y, en el segundo caso, la posesión de un hacha mostraría en forma explícita la relación con la jerarquía de mando.
En los tiempos más tardíos, la relación de tabletas con hachas o mazos resulta ser significativamente relevante. En Quitor 2 tenemos un porcentaje total de tumbas con hachas de $15,5 \%$, en tanto el de tumbas con hacha y además tableta asciende a 85,7\%; en Quitor 5 la relación es de $16,2 \%$ a 55,5\%; en Quitor 6, de 5,2\% a 31,2\%, y en Solcor 3 de $19,5 \%$ a 67,8\%. Con estos resultados se confirma que el acceso al psicotropismo, tanto a través de pipas como de tabletas, desde sus inicios estuvo ligado al estatus de prestigio y en algunos casos de mando, situación que se proyectó por el resto de la etapa precolombina.

En cuanto a la distribución de pipas y tabletas vemos una marcada dicotomía entre la localidad de Toconao y los oasis de San Pedro de Atacama. Al comparar la cantidad total de pipas entre los sitios de los oasis sanpedrinos con el sitio de Toconao, vemos que, proporcionalmente, la presencia de pipas en los oasis es bastante baja. Los 47 ejemplares registrados para los oasis sanpedrinos en el inventario de Gili (2014) se reparten en 16 sitios, obteniéndose un promedio de tres ejemplares por sitio, lo cual contrasta con los 11 registros únicamente para Toconao Oriente.

De las pipas factibles de contextualizar por fases podemos deducir que en Toconao Oriente estas se distribuyen en las fases Toconao, Séquitor y Quitor. En tanto, en los oasis de San Pedro ellas se hacen presentes en las fases Séquitor y Quitor, y no se ha detectado ningún ejemplar asignable a la fase Toconao. A la inversa, las tabletas presentan un amplio predominio entre los sitios de los oasis de San Pedro, tanto en las fases tempranas como en las fases posteriores. En lo que se refiere al aspecto comparativo es interesante destacar el caso de Quitor 8, no solo por presentar el mayor número de tabletas tempranas, sino por la ausencia de pipas.

La práctica de inhalación de sustancias psicotrópicas utilizando tabletas se generalizó rápidamente por todo el ámbito atacameño, proyectándose por el resto de la etapa precolombina. En cambio, la inhalación por medio de pipas no tuvo la misma aceptación, su popularidad fue restringida tanto en el espacio como en el tiempo.

Ambas tradiciones llegaron a la región atacameña como prácticas que se habían consolidado en otros lugares; una de ellas (pipas) hizo su ingreso preferentemente por Toconao y la otra (tabletas) lo hizo preferentemente por los oasis sanpedrinos aunque, paulatinamente, ambas van transfundiendo 
de una a otra localidad. Esta dicotomía sería producto de las diversas vinculaciones que cada uno de estos lugares tenía con distintas localidades transandinas. La primera, se asociaría a un sistema propiamente circumpuneño con mayor relación con el noroeste argentino, en tanto, la segunda, -atendiendo a las tabletas prototiwanaku- tendría conexiones con el altiplano circum-Titikaka meridional.

Esto confirma que en aquellos tiempos estaba funcionando una sofisticada red que no solo involucraba tráfico de objetos domésticos como la alfarería, sino también elementos de carácter ritual, como las pipas y tabletas, impregnados del más alto simbolismo ideológico. Es muy difícil aceptar que artefactos tan especiales como éstos se hayan incorporado a un simple sistema de trueque. Su movilidad en el espacio circumpuneño necesariamente tuvo que tener connotaciones socio-políticas muy especiales. Algunos bienes y objetos, como la alfarería, eran accesibles por esta vía a todos los miembros de la sociedad atacameña; en cambio otros, como las pipas y las tabletas, se movían dentro de ciertas esferas, privilegiando y reforzando los estatus jerárquicos.

Agradecimientos: Por cuarenta años formé parte del cuerpo académico de la Universidad Católica del Norte, buena parte de ellos en el Instituto de Investigaciones Arqueológicas y Museo "R.P. Gustavo Le Paige", en San Pedro de Atacama. Durante ese tiempo tuve la oportunidad -por la cual me siento agradecido- de estudiar las colecciones del museo. El presente artículo es un resultado más de esa dedicación. Mi gratitud va también para los evaluadores por los comentarios y sugerencias que ayudaron a mejorar el manuscrito.

\section{Referencias Citadas}

Ambrosetti, J.B. 1899. Notas de Arqueología Calchaquí, Buenos Aires.

Ambrosetti, J.B. 1908. Exploraciones arqueológicas en la ciudad prehistórica de La Paya (Valle Calchaquí - Provincia de Salta). Publicación de la Sección Antropológica 3(2). Universidad de Buenos Aires.

Berenguer, J., A. Deza, A. Román y A. Llagostera 1986. La secuencia de Myriam Tarragó para San Pedro de Atacama: un test por termoluminiscencia. Revista Chilena de Antropología 5:17-54.

Bird, J.B. y Hyslop 1985. The preceramic excavations at Huaca Prieta, Chicama Valley, Perú. Anthropological Papers of the American Museum of Natural History, Vol. 62, part 1, New York.

Boman, E. 1932. Pipas de fumar de los indígenas de la Argentina. Anales del Museo Nacional de Historia Natural Bernardino Rivadavia 35:309-341.

Dougherty, B. 1972. Las pipas de fumar arqueológicas de la Provincia de Jujuy. Relaciones (N.S.). Buenos Aires.

Fernández Distel, A. 1980. Hallazgo de pipas en complejos precerámicos del borde de la puna jujeña (República Argentina) y el empleo de alucinógenos por parte de las mismas culturas. Estudios Arqueológicos 5:55-75.

Gili, F. 2014. La práctica fumatoria en el Salar de Atacama durante el Período Formativo. Tesis para optar al grado de Magister en Antropología con mención en Arqueología Programa de Postgrado en Antropología, Universidad Católica del Norte y Universidad de Tarapacá.

Hubbe, M., M. Oviedo y C. Torres-Rouff 2011. Estado de conservación y contextualización cronológica de la colección osteológica “Gustavo Le Paige”. Estudios Atacameños 41:29-44.
Ibarra, D.E. y R. Querejazu 1985. 30.000 Años de Prehistoria en Bolivia. Editorial Los Amigos del Libro, Cochabamba.

Krapovickas, P. 1955. El yacimiento de Tebenquiche (Puna de Atacama). Publicaciones del Instituto de Arqueología 3. Buenos Aires.

Krapovickas, P. 1958-59. Arqueología de la puna argentina. Anales de Arqueología y Etnología 14/15:53-113.

Krapovickas, P. 1977. Arqueología de Cerro Colorado (Departamento de Yavi, Provincia de Jujuy, República Argentina). Obra del Centenario del Museo de La Plata 2:123-148.

Llagostera, A., C.M. Torres y M.A. Costa 1988. Complejo psicotrópico de Solcor-3 (San Pedro de Atacama). Estudios Atacameños 9:61-98.

Llagostera, A., C.M. Torres y M.A. Costa 1995. Art in the snuff trays of San Pedro de Atacama (Northern Chile). En Andean Art: Visual Expression and its Relation to Andean Beliefs and Values, editado por P. Dransard, pp. 51-77. Worldwide Archaeology Series.

Llagostera, A., C.M. Torres y M.A. Costa 2001. Archeologia degli allucinogeni in San Pedro de Atacama (Cile del Nord). Eleusis 5:101-121.

Llagostera, A., C.M. Torres y M.A. Costa 2006. Contextualización e iconografía de las tabletas psicotrópicas tiwanaku de San Pedro de Atacama. Chungara Revista de Antropología Chilena 38:83-111.

McRostie, V. 2010. Primeros análisis de microfósiles en la puna salada occidental. Una aproximación a la utilización y cambio morfológico de los morteros de la quebrada de Tulán durante la transición Arcaico-Formativo. Sur del salar de Atacama, II Región, Chile. Actas del XVII Congreso Nacional de Arqueología Chilena (2006), Vol. 2, pp. 1247-1253. Valdivia. 
Núñez, L. 1963. Problemas en torno a la tableta de rapé. Anales de la Universidad del Norte 2:149-168.

Núñez, L. 1969. El primer fechado radiocarbónico del complejo Faldas del Morro en el sitio Tarapacá-40 y algunas discusiones básicas. Actas del V Congreso Nacional de Arqueología, pp. 47-58. La Serena.

Núñez, L., V. McRostie e I. Cartajena 2009. Consideraciones sobre la recolección vegetal y horticultura durante el Formativo temprano en el sudeste de la cuenca de Atacama. Darwiniana $47: 55-56$.

Orellana, M. 1963. Problemas de la arqueología de San Pedro de Atacama y sus alrededores. Congreso Internacional de Arqueología de San Pedro de Atacama. Anales de la Universidad del Norte 2:29-39.

Orellana, M. 1991. Contextos culturales tempranos de Toconao Oriente. Diálogo Andino 10:23-46.

Raffino, R.A. 1977. Las aldeas del Formativo Inferior de la Quebrada del Toro (Prov. de Salta, Argentina). En Obra del Centenario del Museo de La Plata Vol. 2, pp. 253-299. Universidad de La Plata, La Plata.

Rosso, S. y R. Spano 2005/06. Evidencia del uso de alucinógenos en pipas halladas en dos sitios tempranos de los Valles Calchaquíes. Arqueología 13:79-98

Serrano, A. 1966. Manual de la Cerámica Indígena. Segunda edición. Ediciones Assandri, Córdova.

Tarragó, M.N. 1968. Secuencias Culturales de la Etapa Agroalfarera de San Pedro de Atacama (Chile). Actas y Memorias del XXXVII Congreso Internacional de Americanistas, Vol. 2, pp. 119-145. Mar del Plata.

Tarragó, M.N. 1985. Contribución al Conocimiento Arqueológico de las Poblaciones de los Oasis de San Pedro de Atacama en Relación con los Otros Pueblos Puneños, en especial, el Sector Septentrional del Valle Calchaquí. Tesis para optar al Título de Doctor en Historia, especialidad Antropología. Universidad Nacional de Rosario, Rosario.
Thomas, C. y M.A. Benavente 1984. Reflexiones metodológicas acerca de las creencias en la cultura San Pedro a través del análisis de correspondencia de las tabletas de rapé. XLIV Congreso Internacional de Americanistas, Simposio Culturas Atacameñas, pp. 157-174. Universidad del Norte, Antofagasta.

Thomas, C., C. Massone y M.A. Benavente 1984. Sistematización de la alfarería del área de San Pedro de Atacama. Revista Chilena de Antropología 4:49-119.

Torres, C.M. 1984. Iconografía de las tabletas para inhalar sustancias psicoactivas de la zona de San Pedro de Atacama Norte de Chile. Estudios Atacameños 7:178-196.

Torres, C.M. 1986. Tabletas para alucinógenos en Sudamérica: tipología, distribución y rutas de difusión. Boletín del Museo Chileno de Arte Precolombino 1:37-53.

Torres, C.M. 1987. The iconography of South American snuff trays and related paraphernalia. Göteborgs Etnografiska Museu Etnologiska Studier 37.

Torres, C.M. y W.J. Conklin 1995. Exploring the San Pedro de Atacama tiwanaku relationship. En Andean Art: Visual Expression and its Relation to Andean Beliefs and Values, editado por P. Dransart, pp. 78-108. Worldwide Archaeology Series.

Torres, C.M., D.B. Repke, K. Chan, D. Mckenna, A. Llagostera y R.E. Schultes 1991. Snuff powders from prehispanic San Pedro de Atacama: Chemical and contextual analisis. Current Anthropology 32:640-649.

Uhle, M. 1915. Los tubos y las tabletas de rapé en Chile. Revista Chilena de Historia y Geografía 5:114-136.

von Rosen, E. 1924. Popular account of archaeological research during the Swedish Chaco-Cordillera Expedition, 1901-1902. Alb. Bonnier Bohtryckeri, Stockholm.

Westfall, C. 1993-94. Pipas prehispánicas de Chile. Discusión en torno a su distribución y contexto. Revista Chilena de Antropología 12: 123-161.

\section{Notas}

1 El mal estado de conservación de la tableta 3231 de Quitor 8 no permite identificar su representación.
2 El mal estado de conservación de la tableta 947 de Séquitor Alambrado no permite identificar su representación. 
